\title{
SECURE ORGAN TRANSPLANT INFORMATION SYSTEM UDC ((004.65+004.738):004.56.55+(004.56.55:003.26))
}

\author{
Vladan Borović ${ }^{1}$, Saša Borović ${ }^{2}$, Vida Drąsuté $\dot{3}^{3}$ Dejan Rančićc \\ ${ }^{1}$ Ministry of Interior, Belgrade, Republic of Serbia \\ ${ }^{2}$ Dedinje Cardiovascular Institute, Belgrade, Republic of Serbia \\ ${ }^{3}$ Kaunas University of Technology, Kaunas, Lithuania \\ ${ }^{4}$ University of Niš, Faculty of Electronic Engineering, Niš, Republic of Serbia
}

\begin{abstract}
The heart of a modern and efficient information system is a computer database that can be accessed from all over the world. The system demands a strong protection and cryptography, due to a large number of threats in the electronic era. In the well organized transplant programs, all transplantation centers have access to the central computer database. In this important database, the transplantation centers enter information of their recipients along with the recipient profile and the donor profile. This is the basic principle of making the best match between a donated organ and a recipient. This paper elaborates the SetNet information system with potential criminal activities and malpractice regarding the central computer database.
\end{abstract}

Key words: central computer database, web application, data security, cryptography, malpractice

\section{INTRODUCTION}

In January 2017, Serbia became an associate member of EUROTRANSPLANT, which includes more the 135 million inhabitants. Serbia was admitted to this organization on a trial period of one year. During that period our country has to fulfil certain requirements.

According to the Organ Transplant Law from the 2009, and according to the draft law on organ transplants for medical treatment of 2016, the legislator obliges the competent institutions to form a single and unique Republic (National) waiting list for an organ transplant (National organ transplant waiting list).

These are very important tasks and are current topics in the media and on television. Following new world trends in technology, the waiting list should be computerized and

Received January 30, 2017

Corresponding author: Vladan D. Borović

Ministry of Interior, Kneza Miloša 101, 11000 Belgrade, Republic of Serbia

E-mail: vladan.borovic@mup.gov.rs 
secure. Professional objective decision-making algorithms should be implemented, in accordance to the world medical and technical experiences. We live in the times where modern information systems are involved in every aspect of human life. There is a need for computers in the role of deciding and choosing especially if an objective approach is desired. Also, there is a large need for well organized databases that are easily accessed from all over the world. One of the most important aspects is security of data and personal information, identity and objective "jury decisions".

Reliable and, real time and timely information is the basis of decision-making throughout the health system and essential for development and implementation of the policy of the health system, its legislation, research in health, human resource development in the health sector, but also for health education, additional training and education, for providing services and for financing of the entire health system.

The real scenario is: When transplant hospitals accept patients onto the waiting list, the patients are registered in a centralized, national computer database, and introduced into the network that links all donors and transplant candidates. After removal, a donor organ has to be transplanted within a few hours. A smooth running organization is of lifesaving importance. Therefore the central office is manned by specially trained staff, 24 hours a day, and 7 days a week, supported by the computer information system.

In the area of health and medicine, a number of modern applications and databases can be found. In the need of new, modern technologies introduction in Serbia, the professional team made the project and the final product.

The idea for this computer information system is more than 5 years old. A completely new approach was introduced: The accent is on the security with modern methods applied according to the multi-decade experiences in various western countries and their automated and centralized computer information systems.

Also, the idea was to prevent the potential of malpractice and misuse, the criminal activities, and implement modern electronic data security systems with exact human procedures in maintaining the whole system.

There are several levels of security and cryptography applied. Strong mathematics together with a constant database backup and encryption are the basic principles of this new idea. As shown on the next page in Fig. 1, the key and encryption are in the center, the main waiting list in a database with a backup is always accessible from all over the world.

Mobile devices, like PDA's and Android mobile phones are also supported in our system, following the technology development. In this case also, electronic data security and valid patient and donor data are in the first place.

Database table optimization was also an important segment regarding the number of records and their availability, all a part of the database design and planning.

The modern computer information system, as a final product, consists of a well organized database, web application, and a special protection and security. Also, additional decision-making mathematics is added. The main task was that the process of registering and deciding, must be transparent and on a public world network, such as internet. The authentication of authorized personnel has to be very strong together with the encryption of communication and data transmitted. The exchanged data have to be protected because of the large number of persons involved in cybercrime on illegal organ market, and data altering and counterfeiting. 
The whole system is server oriented, the application is hosted and run on a server. Also, the computer database is hosted on a database server which can be hosted on a same computer like web application is, but it is advised that the separate servers manage database and web application, which communicates with a database.

A centralized, national computer database maintained on a hourly and daily basis, together with a modern, well organized web application is what was missing in Serbia, in our society.

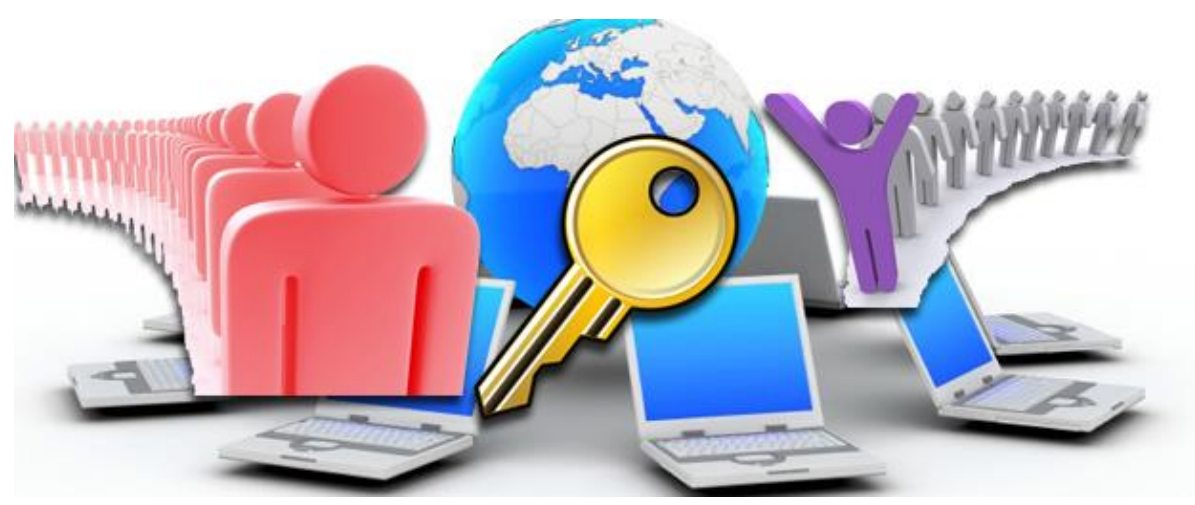

Fig. 1 Secure Organ Transplant Information System representation

This is a professional medical-engineering information system which is a basis of a modern healthcare and of life saving of citizens of one country. Therefore, there is a large number of examples of misusing and malpractice around this multi billion dollars area, which consists of transplant hospitals, medical personnel, governments and administrative personnel, computer databases and applications, donors and transplant candidates.

The benefit from this system is not only in the area of transplantation. There are longterm effects that are expected from developing and advancing the SETNET information system and that are contributing to the development of health care as well as of the whole society. They are:

- System monitoring and regulation of the process of information exchange, to protect the rights and privacy of patients and increase the quality and the efficiency in the delivery of health services.

- Potential for a secondary use of data in an aggregated form for decision-making, improved practice and scientific research, as well as ensuring the openness and transparency of derivative information related to the performance of the health care.

- Meaningfulness, quality and usefulness of the information gathered, their storage, use and publication in a standardized way. This will provide continuity of care and improve the management of chronic health conditions, the outcome of hospital care, and pharmaceutical management.

- Increasing the security of the patients' data and organ matching process with decreasing the financial costs together with improving the cost objectivity. 


\section{THE CURRENT SITUATION IN THE WORLD}

It was proven in many cases that the whole system of donors and transplant candidates, together with transplant hospitals cannot exist without a modern computer information system. This is the practice and real situation in the world.

Two main systems, which were "compasses" of this system's development and building, are:

1) UNOS (USA) [1]

2) EUROTRANSPLANT (Europe) [2]

UNOS is United Network for Organ Sharing based in the United States of America. Their motto is: "Working together, Saving lives".

Their mission is to advance organ availability and transplantation to support patients through education, technology and policy development.

United Network for Organ Sharing (UNOS) is the private, non-profit organization that manages the nation's organ transplant system under contract with the federal government. In doing so, they bring together hundreds of transplant and organ procurement professionals and thousands of volunteers. This unique collaboration helps make lifesaving organ transplants possible each day. Our system serves as the model for transplant systems around the world.

\section{HOW ORGAN MATCHING WORKS}

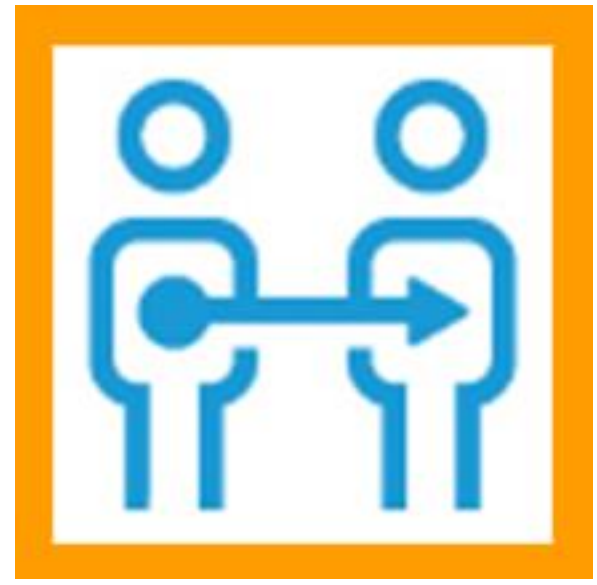

Fig. 2 Donor and a transplant candidate

When a patient is "added to the list," a transplant hospital adds a patient's medical information into UNOS' computer system. When a deceased organ donor is identified, UNOS' computer system generates a ranked list of transplant candidates, or "matches", based on blood type, tissue type, medical urgency, waiting time, expected benefit, geography and other medical criteria [1]. 


\section{IMPORTANT FACTS ABOUT DONORS AND TRANSPLANT CANDIDATES}

- You can be a donor at any age.

- Celebrity or financial status are not factors in getting a transplant.

- Donation is possible with many medical conditions.

- All major religions approve of organ and tissue donation.

- A national computer system and strict standards are in place to ensure ethical and fair distribution of organs.

- A healthy person can become a living donor by donating a kidney, or a part of the liver, lung, intestine, blood or bone marrow. [1]

A national computer system and strict standards are in place to ensure ethical and fair distribution of organs, so the organs are matched by blood and tissue typing, organ size, medical urgency, waiting time and geographic location.

UNOS provides a vital link in the organ transplant process. Its policies and computerized network match donated organs with transplant candidates in ways that save as many lives as possible and provide transplant recipients with the best possible chance of long-term survival. The matching criteria developed by the transplant community, and approved by UNOS' Board of Directors, are programmed into UNOS' computer matching system. Only medical and logistical factors are used in organ matching. Personal or social characteristics such as celebrity status, income or insurance coverage play no role in transplant priority.

EUROTRANSPLANT's motto is: "Cooperating saves lives".

EUROTRANSPLANT is a non-profit organization based in Europe, that facilitates patient-oriented allocation and cross-border exchange of deceased donor organs. Active for transplant centers and their associated tissue typing laboratories and donor hospitals in eight countries, EUROTRANSPLANT ensures an optimal use of donor organs. EUROTRANSPLANT is responsible for the allocation of donor organs in Austria, Belgium, Croatia, Germany, Hungary, Luxembourg, the Netherlands and Slovenia, 8 countries in the Europe. This international collaborative framework includes all transplant hospitals, tissue-typing laboratories and hospitals where organ donations take place.

\section{EUROTRANSPLANT AIMS}

The aims of EUROTRANSPLANT are: As mediator between donor and recipient, EUROTRANSPLANT plays a key role in the allocation and distribution of donor organs for transplantation. The mission statement and goals of EUROTRANSPLANT express the foundation's main target: to ensure an optimal use of available donor organs. The allocation system is based upon medical and ethical criteria. Through conducting and facilitating scientific research, EUROTRANSPLANT aims at a constant improvement of transplant outcomes [9].

Statistical data: [3]

- $\mathbf{1 4 , 5 6 0}$ patients on the active organ waiting list on January 1, 2016.

- $\mathbf{1 0 , 8 0 8}$ registrations on the waiting list in 2015 .

- $\mathbf{7 , 1 4 5}$ organ transplants from deceased donors in 2015

- 134,6 million inhabitants in the EUROTRANSPLANT region 


\section{CENTRAL WAITING LIST IN OUR SYSTEM - SETNET}

SETNET is the name of our system, Serbian Transplant Network (Transplantaciona Mreža Srbije). All transplantation centers within the national transplant system have access to the central computer database. In this database, the transplantation centers enter the general and medical information of their recipients along with the recipient profile and the donor profile. These profiles contain the characteristics of patients and donors (Fig. 3).

Computer information system in SETNET network consists of:

- Hardware components (Servers on the Internet)

- Software components (Web application, RDBMS Database, TLS Protection and Secure Encryption)

Hardware components are Database server (Relational Database Management Server) and a Web server. Both servers can be only one computer.

Software components are copyrighted [4] Web application, Relational Database (MS SQL Server), https TLS (Transport Layer Security protocol) with custom made mathematical algorithms for encryption.

Web application was made in Visual Studio program environment, with program code written in $\mathrm{C \#}$ and $\mathrm{C}++$ programming languages. Web pages are dynamic web pages, in ASPX technology ASP.NET (Active Server Pages) with .NET 4.0, run at server.

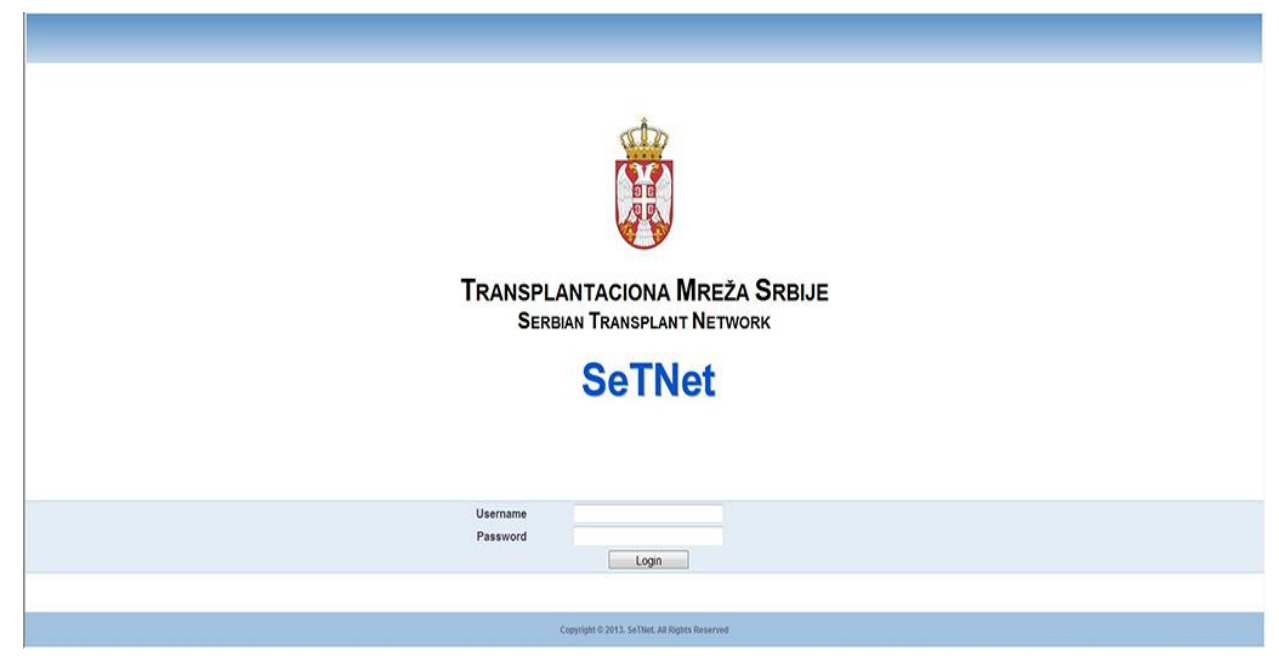

Fig. 3 National computer database (proposed)

Electronic network allows transplant professionals to register transplant candidates on the national waiting list, match them with donated organs, and enter vital medical data on candidates, donors and transplant recipients (Fig. 4). 


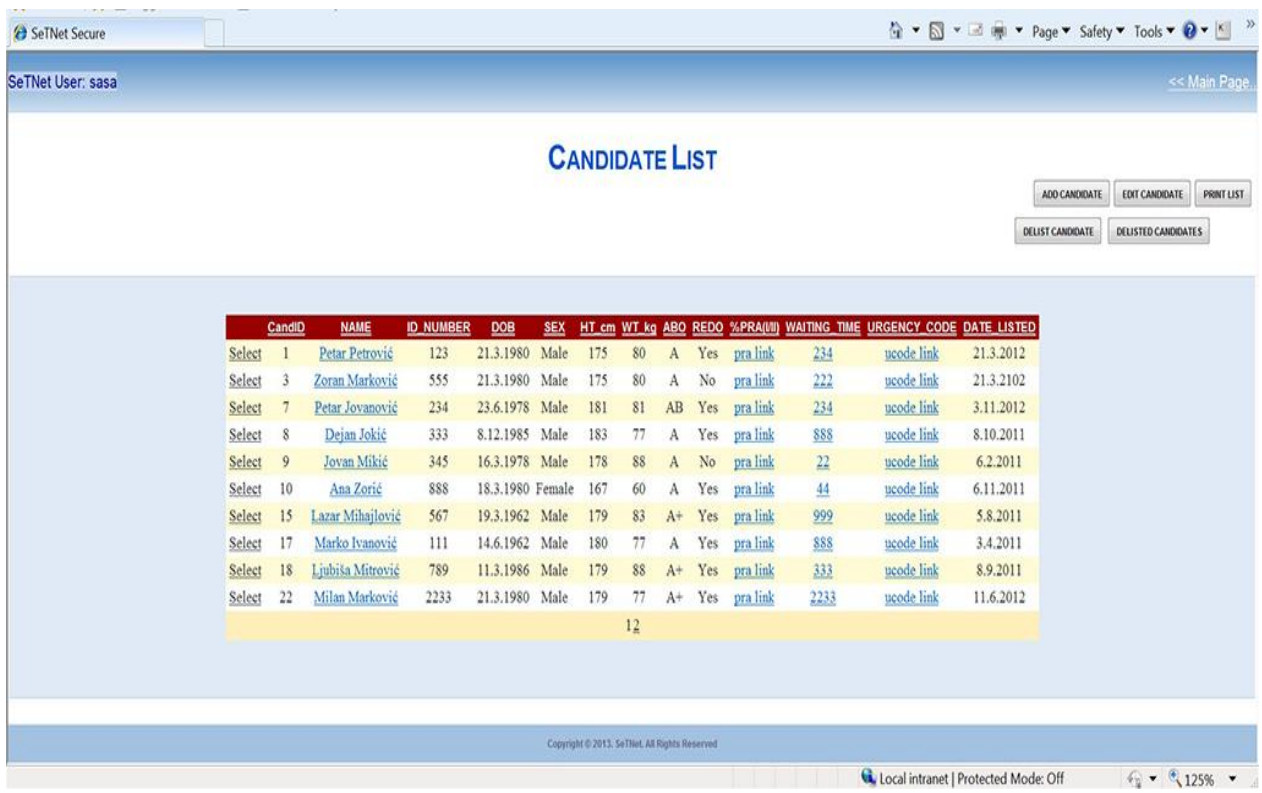

Fig. 4 Candidate list (main page)

When the information is entered into the central database, the patient is put on the waiting list. At that point, the waiting time starts.

\section{AlLOCATION}

Following donor organs identification, the procuring organization accesses the computerized organ matching system, enters information about the donor organs, and runs the match program.

For each donated organ, the computer program generates a list of potential recipients ranked according to objective criteria (i.e. blood type, size of the organ, medical urgency of the patient clinical status, time spent on the waiting list). Each organ has its own specific criteria. The match list is generated by a complicated computer algorithm that takes into account all medical and ethical criteria.

After printing the list of potential recipients, the transplant coordinator contacts the transplant surgeon caring for the top-ranked patient (i.e. patient whose organ characteristics best match the donor organ and whose time on the waiting list and urgency status adhere to allocation policy) to offer the organ. Depending on various factors, such as the donor's medical history and the current health of the potential recipient, the transplant surgeon determines if the organ is suitable for the patient. If the organ is turned down, the next listed individual's transplant center is contacted, and so on, until the organ is allocated.

Once the organ is accepted for a potential recipient, transportation arrangements are made for the surgical teams to come to the donor hospital and surgery is scheduled. For heart, lung, or liver transplantation, the recipient of the organ is identified prior to the 
organ recovery and called into the hospital where the transplant will occur to prepare for the surgery.

The recovered organs are stored in a cold organ preservation solution and transported from the donor to the recipient hospital.

The allocation system is:

1. Objective: the match list is the same no matter which duty desk officer arranges the allocation

2. Reproducible: the same question will lead to the same answer

3. Transparent: every step in the process can be accounted for

4. Valid: the system is based upon valid medical and ethical criteria that are supported by consensus within the transplant community.

The match is based upon general principles of expected outcome, urgency and waiting time. Ethnicity, gender, religion, and financial status are not part of the computer matching system.

\section{MALPRACTICE HAZARDS}

Real-time, detailed communication is essential to coordinate the process of organ donation and transplantation. For many years, most information was shared by phone and fax. As information technology has rapidly evolved, transplant networks developed secure, online-based systems to place organs efficiently and collect essential data to improve the transplant field.

The system is designed for continual operation because any lapse in system availability could mean that transplant candidates lose an opportunity for a life-saving transplant. The system continues to adapt to emerging use of and need for newer technology such as mobile devices and tablets, and to integrate effectively with the increasing use of electronic medical records.

Entry to the computer data system is protected by personal passwords. To ensure as much privacy to donors and recipients, access to data in the system is limited by user rights. The computer based database is accessible over the Internet. This means that it is accessible everywhere there is an internet connection.

There are numerous Cybercrime possibilities. The most common and the most dangerous are:

- Revealing database usernames and passwords

- Changing passwords and important data in a database including patient data and records

- Tracking and sniffing connections on a database

- Sniffing Internet traffic and discovering secret database commands

- Discovering patient identity and medical data

- Deleting a database

- Altering patient urgency and priority

- Misusing private patient data in the area of organ black market in the world [15]

- Demanding a money compensation to illegally change urgency and priority of a patient 
Each transplant center collaborating within national transplant network can enter, update and retrieve their own information of center, recipients, living donors and transplants.

Urgency statuses are used to classify transplant candidates on the waiting list and to prioritize patients in the thoracic organ match and allocation procedure. The urgency statuses reflect transplantability and medical urgency (Fig. 5). The High Urgency (HU) status places the patient in the top priority of receiving the donated organ. The HU status is usually assigned by an independent team of auditors, where their decision is guided by well defined medical criteria [9].

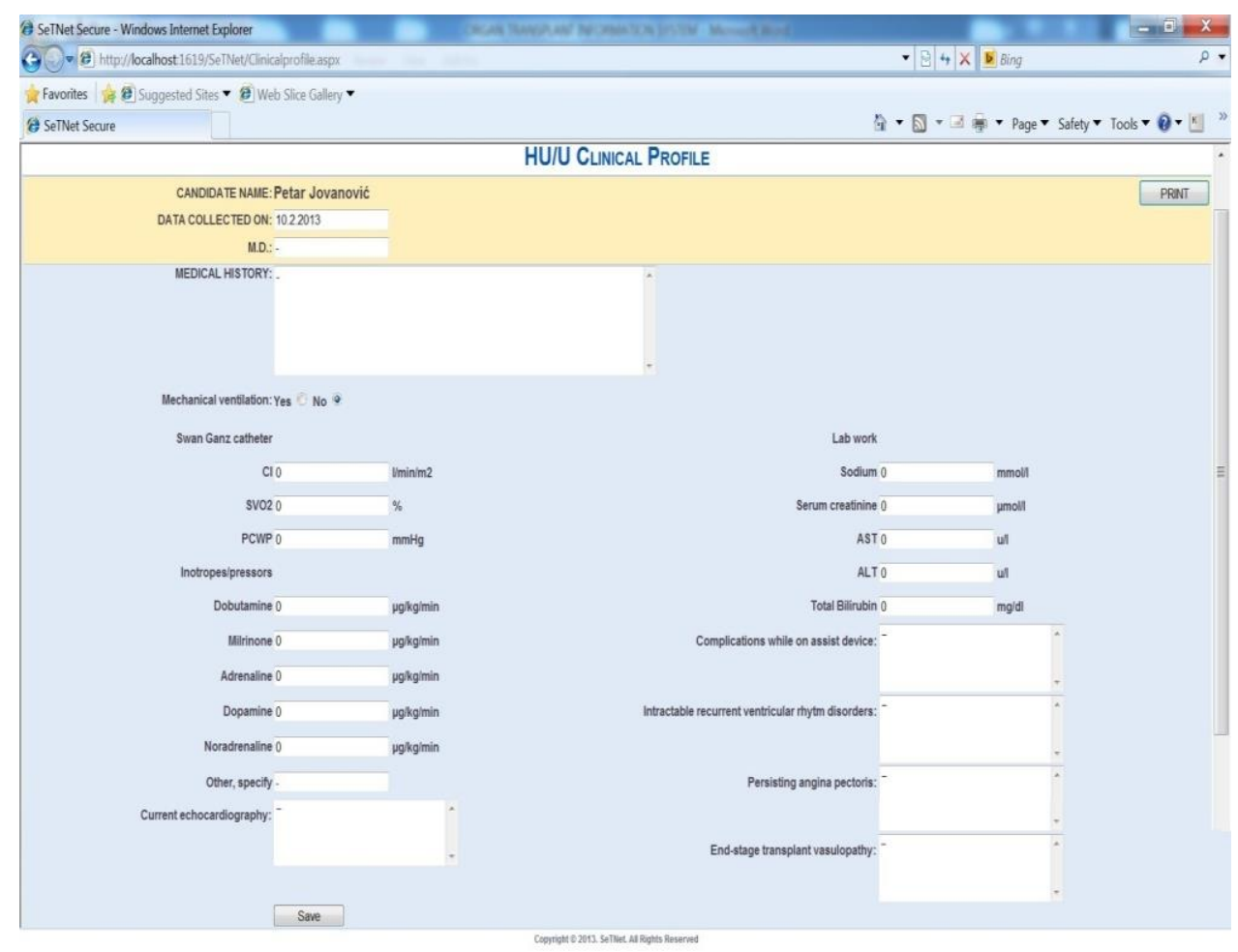

Fig. 5 HU/U clinical profile

Proposing the patient for the HU status opens the possibility for manipulating the organ transplant allocation system in order to help the patients get donor organ more quickly. Doctors could exaggerate the severity of their patients' conditions so that they would be accorded higher priority for receiving organs, by manipulation of medical records. In this scenario, the effective manipulation of organ transplantation would necessitate falsifying medical records and manipulating medical tests. For example, flagging patients as requiring dialysis is likely to move them up the waiting list. Deliberately recording information known to be false constitutes serious misconduct. Tampering with actual medical samples to "make their conditions appear worse" is an extrapolation of the same falsification. Even the TV 
movies are dealing with that subject now [14]. While this is in itself misconduct, the consequences of these actions may also be detrimental to a severely sick patient, by denying them organs, while benefiting another [16].

If we speak about demanding a money compensation to illegally change urgency and priority of a patient, a real example happened in Germany during the period from 2010. till now, according to the numerous internet news [5-8].

\section{MALPRACTICE PREVENTION}

Obviously there are "inner" and "outer" possibilities for the crime, and the prevention should focus on both aspects.

Prevention of "outer" pathway means prevention of the Cybercrime. There are very important steps that must be implemented in a technical organization regarding computer information system, as follows:

- Implementing SSL (Secure Sockets Layer) v3.0 and TLS (Transport Layer Security) protocols for the security, authentication and cryptography, including custom made mathematical algorithms

- Non stop, 24/7/365 technical surveillance on a database and web application users

- Using complex usernames and passwords

- Frequent use of a database backup and patient data check outs

- Monitoring the validity of patient identity

The "inner" pathway is completely depended on the medical profession. Tightly coordinated and monitored national transplantation system should incorporate regulative measures to prevent this kind of crime. Professional (national and international) audits and controls, educated national coordinators and program CEOs are of crucial importance. Evaluation of each transplant program should be routine and transparent. Learning from the experience, national transplant regulatory bodies should be nongovernmental and non profitable.

\section{ADMINISTRATION AND SECURITY MAINTENANCE}

The role of the database Administrator is to assist with the design, installation, security, monitoring, maintenance, and optimization of SETNET database while ensuring high levels of data availability on the Net. This position is also responsible for assisting with developing, implementing, and supervising database policies and procedures to ensure the integrity and availability of all databases and their accompanying software. Administrator's position requires 24/7 and on-call responsibilities.

Among those responsibilities, the main are to:

- Develop and implement monitoring and security plans

- Analyze monitoring data to identify and implement performance improvements

- Manage backup and recovery both on-site and off-site

- Create and implement maintenance plan for regular integrity checks

- Maintain physical organization of database objects

- Apply software upgrades and fixes 
- Plan and manage physical resource requirements

- Administer and enforce standards

- Audit database systems

- Providing status reports to management

- Creates and maintains appropriate documentation

Regarding security, usual tasks are:

- Development of the strong, custom made, mathematical algorithms

- Security requirements gathering and documenting

- Working with the Information Security team to design and document security plan

- Implementing and enforcing security requirements

- Maintaining and improving security in response to industry developments and user experience

\section{CONCLUSION}

In 2016, Integrated Health Information System (IZIS, EU-IHIS) was introduced in the medical care system of the Republic of Serbia. It was funded by the European Union through IPA funds. This project was implemented by the Ministry of Health. Now is the right time to implement this modern, professional Secure Organ Transplant Information System.

There is one interesting fact about this life topic: Organ transplantation is the only medical therapy where benefit of the patient depends on the tragedy of another human. In the era of donor organ shortage, fair and efficient allocation is an imperative. Public confidence and trust in medicine is essential and organ donation and transplantation are no exception. Willingness of members of the public to donate could be undermined by organ transplant scandals.

Use of the modern technologies is the imperative of civilization. Therefore, multidisciplinary taskforce should be responsible to prevent any kind of misuse and crime.

There is an urgent need for a national computer database where the patients are registered, and introduced into the network that links all donors and transplant candidates.

This is a very important project in Serbia done by Serbian scientists, experts, based on the domestic knowledge and "brains", in the area of Medicine, Electro-technical and Information and Communications Technology. Through the years of research and development, including experiences from Houston, Texas, USA, Brussels, Belgium, EU, Germany, Austria, this modern system came to life.

Prevention of Cybercrime can be done by strictly using a protected national computer system with strong encryption and strict standards in organizing the whole system. Security procedures must be obeyed and they have to be written and publicly transparent [12].

One big "Mass donor organ fraud" happened in Germany, European Union, in 2013, which can be a base how to prevent those malpractices and Cybercrime, together with how to fight them. There are even articles and information on prisoner killings for their organs [10]. Atrocities and crimes are made in our country, too [11]. Several appearances of this SETNET network and system occurred on a national TV in Serbia, promoting the importance and necessity of the existence of such a system. 
As mentioned in this paper, the use of the computer information system for managing donors, transplant candidates and transplant hospitals network, together as a whole functional system, is a must, and ethical and fair distribution of organs cannot be managed and successfully be done without a protected computer information system with encrypted, secure communication, data exchange and strong user authentication, proposed in this, SETNET network system.

\section{REFERENCES}

[1] United Network for Organ Sharing (UNOS), 2016. [Online]. Available: https://www.unos.org/

[2] EUROTRANSPLANT, 2016. [Online]. Available: https://www.eurotransplant.org/cms/

[3] EUROTRANSPLANT, Statistical Data, [Online]. Available: https://www.eurotransplant.org/cms/index.php?page=home

[4] Copyright, Saša Borović, Cardio Surgeon M.Sc., Vladan Borović, M.Sc.E.Eng., Authors

[5] Connolly K. Mass donor organ fraud shakes Germany. The Guardian, $9^{\text {th }}$ January 2013. [Online]. Available: http://www.guardian.co.uk/world/2013/jan/09/mass-donororgan-fraud-germany

[6] Turner, L. "'Medical Tourism' Initiatives Should Exclude Commercial Organ Transplantation." J R Soc," Med 101, no. 8 pp. 391-94. 2008.

[7] Turner, L. "Commercial Organ Transplantation in the Philippines." Camb Q Healthc Ethics 18, no. 2 pp. 192-96. 2009.

[8] Berglund S, Lundin S. . "I Had to Leave': Making Sense of Buying a Kidney Abroad." In The Body as a Gift, Resource, and Commodity: Exchanges Organs, Tissues and Cells in the 21st Century, edited by Gunnarson M. and F. Svenaeus, Huddinge: Södertörn Studies in Practical Knowledge, pp. 321-42. 2012.

[9] EUROTRANSPLANT Manual. Chapter 6 March 2016. [Online]. Available: https://www.eurotransplant.org

[10] Killed for their organs, March 2016. [Online]. Available: http://www.stoporganharvesting.org/

[11] Organ Theft in Kosovo, March 2016. [Online]. Available: https://en.wikipedia.org/wiki/Organ_theft_in_Kosovo

[12] Organ trafficking: a protected crime, March 2016. [Online]. Available: http://theconversation.com/organ-trafficking-a-protected-crime-16178

[13] Organ Trafficking: An International Crime Infrequently Punished March 2016. [Online]. Available: www.medicaldaily.com/organ-trafficking-international-crime-infrequently-punished-247493

[14] Why is Kollywood so taken up with organ transplant crimes?, March 2016. [Online]. Available: http://www.thehindu.com/news/cities/chennai/why-is-kollywood-so-taken-up-with-organ transplantcrimes/article7532517.ece

[15] Organ trade, 2016. [Online]. Available: https://en.wikipedia.org/wiki/Organ_trade

[16] Shaw D. "Lessons from the German Organ Donation Scandal," JICS 2013. pp. 14:200-201. 